\title{
Evaluation of the Efficiency of Dental Implants Used in the Oral Rehabilitation in Cleft Patients
}

\author{
Maurício $\mathrm{R}^{1}$, João Luiz C1* Cassia $\mathrm{B}^{2}$ and Antonio de Lima AS ${ }^{1}$ \\ ${ }^{1}$ Departamento de Estomatologia, Universidade Federal do Paraná, Brasil \\ 2Departamento de Cirurgia Bucomaxilofacial do CAIF (Centro integral de Fissurados), \\ Brasil
}

*Corresponding author: João Luiz Carlini, Departamento de Estomatologia, Universidade Federal do Paraná, Avenida Iguaçu, 2820 sala 901 agua verde, 80240-030 Curitiba-PR Brasil, Tel: 5541 999832119; Email: joaoluizcarlini@gmail.com

\section{Abstract}

Cleft patients involving the lip, alveolus and palate is one of the most common malformations in humans. The absence of teeth in the fissure is common and can be rehabilitated by implants and prostheses. The aim of this study was to evaluate the success of the oral rehabilitation of cleft by means of implants in the grafted area.

Material and Methods: In a retrospective analysis of 120 implants installed on cleft areas of 93 patients, mean age = 24.7 years, $48 \%$ female and $52 \%$ male. Of the total implants installed, $94 \%$ were considered osseointegrated. According to the qualitative scale, there were $50 \%$ of success (60 implants), $28 \%$ of satisfactory survival (34 implants), $7.5 \%$ of committed survival ( 9 implants) and $14 \%$ of failure (17 implants). When comparing the osseointegration of the implants with their length, the longer implants $(\geq 10 \mathrm{~mm})$ were 5 times more feasible than the shorter implants $(<10 \mathrm{~mm})(\mathrm{RR}=$ 5.0; $95 \%$ CI $1.014-24.649 ; \mathrm{p}=0.028$ ). The quality of the implants compared to the age of the secondary bone grafting showed that the implants installed in grafted areas at the ideal age, between 7 and 11 years, presented better quality than those installed in grafted areas above this age $(\mathrm{p}=0.001)$.

Conclusion: Implants are feasible in rehabilitation, and the largest implant length should be chosen. The quality of the implants is increased when the secondary graft is performed between 7 and 11 years of age.

Keywords: Cleft Palate; Dental implants; Alveolar Bone Graft

\section{Introduction}

The clef patients alveolus and palate is one of the most common malformations among humans. It affects between 1: 700 and 1: 500 births and requires multidisciplinary treatment for the functional and aesthetic rehabilitation of the patient [1]. The principle that governs the treatment is the local anatomical reconstruction, being the first surgical interventions performed in the lip and palate, still, during the first year 


\section{Open Access Journal of Dental Sciences}

of life. These procedures allow speech, breathing and chewing functions to be performed by the patient as soon as possible, avoiding or reducing functional, nutritional and developmental sequelae [2]. The closure of the oronasal fistula and alveolar bone grafting (secondary grafting) are performed together with the orthodontic treatment between 7 and 11 years of age. The surgical procedure at the correct age allows eruption of the permanent dentition in the maxillary arch and remodelling of the graft forming the bone alveolus at the cleft site [3].

The absence of one or more teeth in the permanent dentition is reported in up to $66.5 \%$ of the fissured individuals [4]. In addition, diseases that affect the formation of dental tissues (microdontia, dentinogenesis or imperfect amelogenesis) are common in teeth adjacent to the cleft, especially in the lateral incisors [5]. It can be expected that in all the fissured there is some abnormality in anterior teeth [6]. These diseases interfere in the quality of the dental tissue that associated with the lack of local bone support and the need to remove the teeth that can interfere during the grafting, lead to a large number of absences among the alveolar fissures. With this absence of anterior teeth, occlusal problems occur that cannot be corrected by orthodontic treatment alone and may cause anterior teeth to retract, loss of overjet and deviation of the midline. To reduce or avoid these problems, the use of implants and prostheses on implants in the prosthetic space of missing teeth is indicated. This feature allows a bilaterally proportional maxillary alveolar perimeter suitable for occlusal closure with the arch mandibular [7]. The first report of the use of osseointegrated implants in patients with cleft palate was [8] in 1991, followed by successive reports of this successful use [9-12]. In 1997 [13] published the first series of cases proving the effectiveness of implants in cracks.

In response to this author [14], stated that the use of dental implants for the rehabilitation of patients with fissures is already a common practice, however studies with the clinical situations of this treatment and longterm study were still needed. Carried out a systematic review [15], based on 11 articles that accompanied 484 implants installed in grafts reconstructed by grafting, and concluded that treatment with grafts and dental implants in fissured patients is feasible in the short term, less than 5 years, but the success rate in conjunction with perimplant clinical parameters are still required in evaluations above 5 years. In another systematic review [16] of 18 articles that accompanied 670 dental implants in fissures, showed a high success rate according to the authors (88.6\%), with a 5-year follow-up after their installation.

The aim of this study was to analyze osseointegration and the quality of osseointegrated implants installed in alveolar fissures reconstructed by bone grafts in relation to the factors that make up the rehabilitating treatment of cleft palatal lip.

\section{Material and Methods}

For the analysis of the osseointegration and the quality of the implants installed in anatomical regions with fissures, a survey of the files of patients with cleft alveolar submitted to the rehabilitation of the cleft areas with dental implants was performed in the Centre of integral care to the fissured lip -(CAIF) - Curitiba / PRBrazil, from January 2000 to December 2014. A total of 338 medical records were requested from the service secretariat and according to the inclusion and exclusion criteria, 93 were included in the study. Patients being both male and female, with either unilateral or bilateral fissures, submitted to bone grafting at CAIF and with medical records for data collection.

\section{Data Collect}

A form to fill in the information contained in the medical record was prepared to assist in data collection. Each chart was numbered so that patient identification was not necessary. The following variables were analyzed:

a) Age of the patient when the bone grafting was performed in the fissured area;

b) Classification of the fissure [17];

c) The graft donor area in the fissure;

d) If there was postoperative complication of grafting;

e) If there was a need for surgical supplementation of the graft;

f) Age of patient performing dental implant surgery in the area

g) Fissured;

h) Commercial brand of dental implant;

i) Size of the dental implant;

j) Time of installation of the prosthesis on the dental implant;

k) Specification of the prosthesis installed on the dental implant;

l) Time of follow-up post-installation of the prosthesis on the dental implant; 


\section{Open Access Journal of Dental Sciences}

m) If there was osseointegration of the implant, and the prosthesis remained on the implant for at least 6 months after its installation.

Measure of bone loss in millimeters in the mesial and distal region of the implants installed in the fissured area. This measure was performed by a single operator, the difference being between the distance from the beginning of the implant to the bone margin between the radiographs performed shortly after the installation of the implant on the implant and the follow-up radiography

a) Presence of mobility or suppuration during treatment through annotations in the medical records performed by professionals.

b) Classification of Misch [18]

\section{Statistical Analysis}

The data was scanned into a spreadsheet of Excel for Mac software version 15.13.1 Microsoft 2015. Fischer's exact test was then applied for comparison of the data in the SPSS program IBM Statistics Desktop 22.0 for Base and all Modules Mac OS X Multilingual Assembly. In Fischer's scale the number of implants was evaluated quantitatively as a function of time (considered at least 6 months); the mean age of the patients, sex and the mean time of installation of the prosthesis over the implants. Where the following items were evaluated in the qualitative aspect, based on the Misch classification: the integration of the implants in relation to their survival, in relation to the length of the implants used and in relation to the age at which the bone graft was performed.

\section{Results}

Of the total of 120 implants installed in 93 patients, 113 (94.2\%) implants remained with the prosthesis installed for at least 6 months. The mean age of the patients at implant installation was 24.7 years, ranging from 13 to 50 years of age, being $48 \%$ female and $52 \%$ male. The mean time of installation of the prosthesis after implant surgery was 18.7 months, ranging from 5 to 111 months and the time of follow-up of the prostheses was on average 6.1 years, varying from 1 to 15 years. Of the seven implants lost, two implants were replaced, two patients chose to install a fixed prosthesis, one continued the treatment in another state and two did not return after the loss.

The implants were submitted to a qualitative analysis according to the scale of Misch, et al. [18]. The results showed the following distribution: $50 \%$ of success ( 60 implants), $28.3 \%$ of satisfactory survival (34 implants), $7.5 \%$ of committed survival ( 9 implants) and $14.2 \%$ of failure (17 implants).

The age of secondary grafting was statistically relevant with higher implant quality in the group that performed the surgery at the ideal age $(\mathrm{p}=0.001)$. In the comparison regarding osseointegration although all the failures were in the group above the ideal age, 7 losses, no statistical difference was observed $(\mathrm{RR}=1.091: 95 \%$ CI 1.023 $1.164, \mathrm{p}=0.074)$. Table 1 shows the distribution of qualitative scale data.

Misch Rating

\begin{tabular}{|c|c|c|c|c|c|}
\hline Age Ideal & Sucess & Survival Satisfactory & Survival Committed & Failure & Total \\
\hline Yes & 28 & 5 & 2 & 1 & 36 \\
\hline No & 32 & 29 & 7 & 16 & 84 \\
\hline Total & 60 & 34 & 9 & 17 & 120 \\
\hline
\end{tabular}

Table 1: Quality Distribution of Implants Installed In Fissured Palatal Lips by the Age of Secondary Enxery.

The length of the implants in the cleft areas was statistically different with five times greater integration in long implants $(\mathrm{RR}=5.0 ; 95 \%$ CI 1.014- -24.649; $\mathrm{p}=$ 0.028 ), where there were 5 losses in 46 short implants. On the other hand, long implants presented 2 losses in 74 implants. Regarding the quality of these implants (although long implants had more success than short implants), $55 \%$ and $41 \%$ respectively, this relation was not statistically proven $(\mathrm{p}=0.164)$. Table 2 shows the distribution of integration data.

\begin{tabular}{|c|c|c|c|}
\hline Lengthimplants & Sucess & Sucess & Total \\
\hline & Yes & No & \\
\hline Short & 41 & 5 & 46 \\
\hline Long & 72 & 2 & 74 \\
\hline Total & 113 & 7 & 120 \\
\hline
\end{tabular}

Table 2: Distribution of the osseointegration of the implants installed in fissured palatal liquids according to its length. 


\section{Open Access Journal of Dental Sciences}

When unilateral and bilateral fissured individuals were compared to dental implants, unilateral fractures were $97 \%$ successful (72 osseointegrated in 74 implants) and bilateral fractures $89 \%$ successful (41 osseointegrated in 46 implants). Values that did not statistically show difference $(\mathrm{RR}=0.228 ; 95 \%$ CI 0.042 $1.227, p=0.063$ ). As to the quality of the implants in these two groups, a trend of greater success was observed in unilateral individuals (41 implants with success in 74 implants) compared to bilateral implants (19 implants in 46 implants), but the groups also had no difference $p=$ 0.92). Regarding the donor area of the cleft reconstruction graft, complementation of graft and implant marking, the groups showed no statistical difference in osseointegration and implant quality. As for the donor area in which the group and iliac crest are compared, a relation of $p=0.152$ and $p=0.943$ was obtained for osseointegration and quality respectively. For groups with or without graft complementation, implant placement indicated $p=0.989$ and $p=0.427$ for the same clinical parameters, respectively.

Two commercial brands of implants were compared, Neodent $₫$ and Signo Vinces $®$. The results showed that there was no statistical difference between the groups regarding osseointegration and quality $(\mathrm{p}=0.907$ and $\mathrm{p}=$ 0.377).

\section{Discussion}

The osseointegration rate of $94.2 \%$ of the total dental implants installed in areas of fissures corroborates with the literature findings that have similar rates in implants installed in non-cracked areas (94\%, 95\%, 98\%) [18-20] and in fissured areas $(82 \%, 90 \%$ and $98 \%)[13,21,22]$.

This percentage was also significantly close to the rates of osseointegration of implants in non-cracked patients who were previously grafted to increase local bone volume, 96\% [23] and 97\% [24]. These findings reinforce the hypothesis that dental implants are effective in dental rehabilitations in the clinical conditions presented by the cleft alveolar palatal as well as in patients who are not cracked, with previous grafts or not. The smaller success of short implants $(<10 \mathrm{~mm})$ compared to long implants ( $\geq 10 \mathrm{~mm}$ ) is a reason for great discussion in the literature. Some authors point to clinical advantages in using longer implants, which include an increase in initial stability, greater long-term resistance to tensile and torsional forces, and a decreased risk of movement at the implant interface. However, there is no consensus that smaller implants present greater loss [2527].
In the present study, a 5 -fold loss rate was observed for short implants when compared to long implants. The use of short implants in fissures is common because the bone volume of the secondary graft undergoes a resorption of up to $55 \%$ of its volume [27]. Thus, due to the greater probability of loss, it is recommended to use the largest possible length in the implants to be installed in these areas. However, the results of the present study do not contraindicate the installation of short implants, since of the 41 short implants used in this study, 87\% (36 implants) obtained osseointegration.

In fissures grafted at the ideal age, the eruption of the canine tooth in the grafted alveolus maintains a greater local bone quantity [3]. In these patients, a higher quality of installed implants was observed, and this could be pointed out as an indication of graft reconstruction surgery being performed during the ideal age. The limitation of the study in proving the greater osseointegration of the implants in patients where the reconstruction of the cleft was performed at the ideal age can be attributed to the insufficient sample size, since the ideal age group obtained $100 \%$ osseointegration.

No statistical difference was found regarding the classification of cracks. However, it was observed that $97 \%$ of the cases of patients with unilateral fissures obtained osseointegration. On the other hand, in individuals with bilateral fissures, osseointegration occurred in $87.8 \%$ of the sample. Taking into account that the literature [27-29] indicates the greater resorption of the grafts in bilateral fissures, this fact suggests the hypothesis that there may be a greater loss of the implants in places with less bone quantity.

The iliac crest and the mentum are reported as possible donor sites for the secondary graft in fissures $[2,6,30]$. In the present study, no statistical difference was observed regarding the osseointegration and quality of the implants installed in the areas that received bone from these two sites of origin of the grafts.

One of the factors in which one could expect greater success of the implants would be the grafting complementation prior to its installation. With increased local bone volume, longer implants could be installed, but this relationship has not been proven. Of the total of implants installed $32 \%$ in fissures that had complementation of the graft and 35\% in fissures without complementation of the graft were of short implants. In addition, in none of them was there statistically higher osseointegration or quality. 


\section{Open Access Journal of Dental Sciences}

Although the literature indicates variable indexes of osseointegration and quality in different brands of dental implants [29-33], the two trademarks analyzed did not demonstrate significant difference in this study. Based on these results, it can be concluded that dental implants are viable in the rehabilitation of cleft lip and palate. It is preferable to install implants with longer lengths in cracked regions. Finally, secondary grafting surgery should be performed at the ideal age, as it may contribute to increase the quality of dental implants installed in the cleft lip and palate.

\section{Conclusion}

The dental implants are viable in the rehabilitation of cleft lip and palate, presenting in this study an osseointegration rate of $94 \%$. Regarding the clinical aspects of the fissures and rehabilitation surgeries of these cracks, the use of short dental implants had five times greater loss than when compared to the use of long implants. The bone grafting surgery that was performed at the ideal age obtained higher quality of the implants when compared to reconstruction surgery that was performed above the ideal age. The other factors analyzed were: fissure classification, graft donor area, need for graft complementation and implant marking had no influence on osseointegration and on the quality of the implants used for the rehabilitation of the cleft palate.

\section{References}

1. Abyholm FE, Bergland O, Semb G (1981) Secondary bone grafting of alveolar clefts. A surgical/orthodontic treatment enabling a nonprosthodontic rehabilitation in cleft lip and palate patients. Scand J Plast Reconstr Surg 15(2): 127-140.

2. Albrektsson T, Zarb G, Worthington P, Eriksson AR (1986) The long term efficacy of currently used dental implants: A review and proposed criteria of success. Int J Oral Maxillofac Implants, United States, 1(1): 11-25.

3. Anastassov GE, Joos U (2001) Comprehensive management of cleft lip and palate deformities. J Oral Maxillofac Surg 59(9): 1062-1075.

4. Boehn A (1963) Dental anomalies in harelip and cleft palate. Acta Odont Scand Englad 21: 31-109.

5. Boronat A, Carrillo C, Penarrocha M, Pennarocha M (2010) Dental implants placed simultaneously with bone graft in horizontal defects: a clinical retrospective study with 37 patients. Int J OralMaxillofac Implants 25(1): 189-196.

6. Boyne PJ, Sands NR (1972) Secondary bone grafting of residual alveolar and palate clefts. J Oral Surg 30(2): 87-92.

7. Carmichael RP, George KB (2008) Use of Dental Implants in the Management of Cleft Lip and Palate. Atlas Oral Maxillofacial Surg Clin North Am 16(1): 6182.

8. Verdi FJ, Lanzi GL, Cohen SR (1991) Use of Branemark implant in the cleft patient. J Cleft Palate Craniofacial 28(3): 301-303.

9. Derks J, Håkansson J, Wennström JL, Tomasi C, Larsson M, et al. (2015) Effectiveness of implant therapy analyzed in a Swedish population: early and later implant loss. J Dent Res 94(3): 44-51.

10. Epstein LJ, Davis WB, Thompson LW (1971) Delayed bonegrafting in cleft palate patients. Plast Reconstr Surg 46(4): 363-367.

11. de Barros Ferreira S, Esper LA, Sbrana MC, Ribeiro IW, de Almeida AL (2010) Survival of dental implants on cleft área - A retrospective study. Cleft Palate Craniofac J 47(6): 586-590.

12. Gonçalves TM, Bortolini S, Martinolli M, Alfenas BF, Peruzzo DC, et al. (2015) Long-term short implants performance: Systematic review and meta-רanalysis of the essential assessment parameters. Braz Dent J 26(4): 325-336.

13. Takahashi T, Fukuda M, Yamaguchi T, Kochi S (1997) Use of endosseous implants for dental reconstruction of patients with grafted alveolar clefts. J Oral Maxillofac Surg 55(6): 576-583.

14. Chiapasco M (1997) Use of endosseous implants for dental reconstruction of patients with grafted alveolar clefts. J Oral Maxillofac Surg 55: 584.

15. Wang F, Wu Y, Zou D, Wang G, Kaigler D (2014) Clinical outcomes of dental implants therapy in alveolar cleft patients: a systematic review. Int J Oral Maxillofac Implants 29(5): 1098-1105.

16. Wermker K, Jung S, Joos U, Kleinheinz J (2014) Dental implants in cleft lip, alveolus and palate patients: a systematic review. Int J Oral Maxillofac Implants 29(2): 384-390. 


\section{Open Access Journal of Dental Sciences}

17. Spina V, Psillakis JM, Lapa FS, Ferreira MC (1972) Classification of cleft lip and cleft palate. Suggested changes. Rev Hosp Clin Fac Med São Paulo 27(1): 5-6.

18. Misch CE, Perel ML, Wang HL, Sammartino G, GalindoMoreno P (2008) Implant success, survival, and failure: the international Congress of oral implantologists (ICOI) Pisa concensus conference. Implant Dentistry 17(1): 5-15.

19. Kramer FJ, Baethge C, Swennen G, Bremer B, Schwestka-Polly R, et al. (2005) Dental implants in patients with orofacial cleft: a long-term follow-up study. Int J Oral Maxillofac Surg 34(7): 715-721.

20. Levin L, Nitzan D, Schwartz-Arad D (2007) Success of dental implants placed in intraoral block bone grafts. J Periodontol 78(1): 18-21.

21. Matsui $Y$, Ohno K, Nishimura A, Shirota T, Kim S (2007) Long-term study of dental implants placed into alveolar cleft sites. Cleft Palate Craniofac J 44(4): 444-447.

22. de Menezes LM, Deon Rizzatto SM, Fabiane Azeredo, Diogo Antunes V (2010) Characteristics and distribution of dental anomalies in a Brazilian cleft population. Rev Odonto Ciência 25(2): 137-141.

23. Olin WH (1964) Dental anomalies in cleft lip and palate patients. Angle Orthod 34(2): 119-123.

24. Fraunhofer JA (2005) Success or failure of dental implants? A literature review with treatment considerations. Gen Dent 53(6): 423-432.

25. Ronchi P, Chiapasco M, Frattini D (1995) Endosseous implants for prosthetic rehabilitation in bone grafted alveolar clefts. J Craniomaxillofac Surg 23(6): 382386.
26. Phillips JH, Nish I, Daskalogiannakis J (2012) Orthognathic surgery in cleft patients. Plast Reconst Surg 129(3): 535-548.

27. Karoussis IK, Brägger U, Salvi GE, Bürgin W, Lang NP (2004) Effect of implant design on survival and success rates of titanium oral implants: a 10-year prospective cohort study of the ITI ${ }^{\circledR}$ Dental Implant System. Clinic Oral Implants Research 15(1): 8-17.

28. Winkler S, Morris HF, Ochi S (2000) Implant survival to 36 months as related to length and diameter. Ann Periodontol 5(1): 22-31.

29. Van der Meij AJ, Baart JA, Prahl-Andersen B, Valk J, Kostense PJ et al. (2001) Bone volume after secondary bone grafting in unilateral and bilateral clefts determined by computed tomography scans. Oral Surg Oral MedOral Pathol Oral Radiol Endod 92(2): 136-141.

30. Timothy A Turvey, Katherine Vig, John Moriarty, Jim Hoke (1984) Delayed bone grafting in the cleft maxila and palate: a retrospective multidisciplinary analysis. Am J Orthod 86(3): 244-256.

31. Sperber G (2002) Formation of the primary and secondary palate. In: Cleft lip and palate: from origin to treatment. New York: Oxford University Press, pp: $5-24$.

32. Jensen J, Sindet-Pedersen S, Enemark H (1998) Reconstruction of residual alveolar cleft defects with one-stage mandibular bone grafts and osseointegrated implants. J Oral Maxillofac Surg 56(4): 460-466.

33. Samama Y, Tulasne JF (2014) Dental sequellae of alveolar clefts: Utility of endosseous implants. Part I: Therapeutic protocols. Int Orthod 12(2): 303-344. 